\title{
Managing small to medium enterprises suppliers in developing countries- A case of SMEs in Harare, Zimbabwe
}

\author{
Michael Musanzikwa \\ Lecturer at Chinhoyi University in the Department of Supply Chain Management \\ Email address: \\ michaelmusanzikwa@yahoo.co.uk
}

To cite this article:

Michael Musanzikwa. Managing Small to Medium Enterprises Suppliers in Developing Countries- A Case of SMEs in Harare, Zimbabwe. Science Journal of Business and Management. Vol. 2, No. 1, 2014, pp. 35-43. doi: 10.11648/j.sjbm.20140201.15

\begin{abstract}
The purpose of this paper is to provide an overview of the challenges which are being experienced between the buying organizations and the Small to Medium Enterprises Suppliers (SMEs) in the Supply Chain in Zimbabwe. Objectives of the study are to assess the role of SMEs in the economic development, to analyze challenges faced when dealing with SMEs in procurement, to identify factors that hinder SMEs from being reliable partners in supply chain, and to come up with strategies for ensuring that SMEs become reliable partners in supply chain. This study adopted a qualitative research design because it provided flexibility and afforded the researcher the opportunity to conduct an in-depth research. The population for this study was made up of 595 SMEs suppliers in the Harare central business district (CBD) and 20 officials from the Small Enterprises Development Corporation (SEDCO). This study used stratified random sampling technique when selecting participants from SMEs suppliers while SEDCO officials were selected using simple random sampling. The study showed that SMEs were important to the economic development of Zimbabwe and there was a need for companies to support them through procurement. Nevertheless, it was held that SMEs suppliers were very unreliable, provides poor quality materials and performed below standard. The study revealed that ignorance about the importance of accounting information, lack of capacity, and lack of separation between ownership and management of SMEs hindered some organizations from being accountable. It is recommended that adoption of professional procurement ethics is important, need for supplier evaluation, effective communication, and the need for SMEs to formalize their business operations and maintain accounting records. There is a need for separation of ownership and control of business affairs. This would ensure more accountability.
\end{abstract}

Keywords: Procurement, Small to Medium Sized Enterprises, Supply Chain

\section{Introduction}

SMEs in Zimbabwe have been regarded as important players in the contribution to the economic growth of the country and the government has made tremendous efforts to recognize and promote them into the mainstream of the economy. However their relationship with well-established buying organizations in the private sector and in the public sector has been very cozy. Both the private and public sectors accuse the majority of the SMEs suppliers as inefficient and letting them down in achieving the targeted lead times thereby failing to obtain value for money in their business organizations.

On the other hand the SMEs have raised concerns that in both sectors they are not being fully supported to obtain big supply contracts besides their readiness to participate in economic mainstream. For example they highlighted that the public sector was the main culprit as it disregarded the Government Statutory Instrument 171 of 2002 which compels Government to contract local companies.

Besides these counter accusations the private and public sector have acknowledged that the SMEs have got an important role to play in the supply chain and contribute positively to the growth of the economy. This is because SMEs are equally critical partners in the buyer's business organization and they become part of the production process in the buyer's business operations so as to achieve organizational goals. This means that there is need to manage the SMEs suppliers in developing countries so as to amend the conflict so that organizational objectives are achieved for the benefit of the country. 


\section{Research Objective}

The researcher sought to attain a number of objectives. These were;

- To assess the role SMEs in economic development.

- To analyze challenges faced when dealing with SMEs in procurement.

- To identify factors that hinders SMEs from being reliable partners in supply chain.

- To come up with strategies for ensuring that SMEs become reliable partners in supply chain.

\section{Literature Review}

\subsection{Definition of Key Terms}

- Procurement: It is a process of identifying and obtaining goods and services. It includes sourcing, purchasing and covers all activities from identifying potential suppliers through to delivery from supplier to the users or beneficiary. It is favorable that the goods/services are appropriate and that they are procured at the best possible cost to meet the needs of the purchaser in terms of quality and quantity, time, and location [23].

- $\quad$ Small and Medium-Sized Entities (SME): The Small and Medium-Sized Entities (SME) can be characterized into three categories; micro, small and medium-size enterprises. They are small businesses employing less than 100 employees [31]. The basic requirements for Small and Medium-Sized Entities (SME) are companies that do not have public accountability, and prepare general purpose financial statements for external users [14].

- Supply Chain: [41] argues that supply chain (SC) is the management of a network of interconnected business involved in the provision of product and service packages required by the end customers in a supply chain. [29] Contends that SC is the design, planning, execution, control and monitoring of supply chain activities with the objective of creating net value, building a competitive infrastructure, leveraging worldwide logistics, synchronizing supply with demand and measuring performance.

\subsection{Theoretical Framework}

The researcher believes that, due to dynamism of the environment, there is a need to continuously improve SMEs operations. Accordingly, this study applies the Kaizen Continuous Improvement model that was popularized by [27]. [27] Argues that there is one important question to ask when dealing with procurement. The question is; "How is the organization seeking continuous improvement in its approach to procurement for new development, planned and responsive maintenance?" To ensure improvement in procurement, [27] prescribes that organizations should use 'best value' techniques, which embody aspects such as challenging what organizations should do and how they do it, making comparisons with others, consulting people affected by the organization's services, and establishing that value for money is obtained during procurement.

\subsection{Role of Procurement in Supply Chain}

[21] Agitate that procurement is a key activity in the supply chain. Procurement can significantly influence the overall success of an emergency response depending on how it is managed. In most organizations, procurement represents a very large proportion of the total spend and should be managed effectively to achieve optimum value. Procurement works like a pivot in the internal supply chain process turning around requests into actual products/commodities or services to fulfill the needs [4]). [4]) further argue that procurement serves three levels of users and these are the internal customer, programs in response to emergencies and on-going programs, and prepositioning of stocks, for both internal customers and program needs.

In addition, [2] contend that the overall aim and objective of procurement is to carry out activities related to procurement in such a way that the goods and services so procured are of the right quality, from the right source, are at the right cost and can be delivered in the right quantities, to the right place, at the right time. There are 'six rights' in procurement and they can be achieved through the following specific objectives of procurement [2]. These specific objectives are;

- To buy quality materials, items and services economically from reliable sources;

- To ensure timely delivery through the selection of capable and efficient suppliers;

- To continuously locate, evaluate and develop economical and reliable supply sources;

- To identify the most reliable sources of supply through either open tender, multi-stage tendering (prequalifying suppliers and retaining only those that are capable of meeting the organization's requirements; strategic sourcing) and limited tendering.

- To investigate the availability of new materials and monitor trends in market prices

- To buy in accordance with organizations policies

Moreover, [4]) says that there are the three important principles of procurement. The first principle is transparency, which provides that all phases in the procurement process are fair and accurately documented. The second principle is that of accountability and it points out that there is need for accountability to financiers, who may require certain rules to be followed when using the money they have provided. Finally, there is the principle of efficiency and cost effectiveness and this principle is about meeting the 'six rights' of supply (price, right time, right quantity, quality services, and delivery to the required places and from the most cost effective source).

Procurement has an important role to play and according 
to [39], every organization should put in place effective systems of procurement to protect shareholders funds. The procurement function forms a key part of any management strategy. The particular features of procurement are the budgets involved, the frequency of activities and technical complexity of the functions. More recently as a function procurement has been complicated by the inclusion of 'manufacturing partnering' and by the acceptance that best value cannot be measured by price alone, but needs to take account of time, quality and sustainability considerations as well [39].

\subsection{Role of SMEs in Economic Development}

According to [22], small businesses are the engines for economic growth in a country. Therefore, the private sectors of many emerging economies today are let down by a 'missing middle' [8] Investors, policymakers and development professionals wrongly dedicate most of their efforts to either large corporations of over 500 employees and pay little or no attention to SMEs [19]. Larger enterprises and multi-national corporations (MNCs) are frequently the main targets for tax incentives and corporate subsidies. Nevertheless, SMEs are vital in any economy and institutions like the World Bank and United Nations Development Program have devoted a significant amount of attention and aid towards promoting micro-enterprises [28]. SMEs are often seen as being too minute to serve as significant drivers of economic growth (and therefore unworthy of policy consideration by governments), yet too large to benefit from non-profit and microfinance institution schemes such as joint-liability programs. [25] highlighted that structural changes to the economy should be noted. For example Zimbabwe had some big companies that closed meaning that employment is below $20 \%$ in the formal sector. Consequently this information implies that employment is $80 \%$ high in the informal sector so approaches must be made to engage the SMEs on the way forward as they are positive contributors to the economy. While the challenges to the SME sector can be daunting, there have been many promising initiatives to support this crucial sector in emerging economies. There has been action by civic, investment and business leaders who recognize the clear role of SMEs in sustainable development [40].

Consequently, definitional issues and a paucity of data in some areas make any analysis of SMEs impacts difficult. For example, the role SMEs play in community development often remains obscured by the informal nature of their actions, a phenomenon that is often called 'silent corporate social responsibility' [16]. However, anecdotal and quantifiable evidence exists in a number of studies on small business and the environment, providing a sense of how important this sector is for sustainable development in emerging economies. In this regard, [15]) concluded that SMEs, being less mobile than large corporations, are more likely to have ties of dependence and familiarity to their communities, which will ensure they protect their reputation and relationships among neighbors and customers. Also, a study of European SMEs noted that on average, $67.5 \%$ of SMEs practiced some form of external socially responsible activity on a regular basis, such as supporting a local charity [12].

Moreover, the presence of SMEs also correlates with several economic factors, including the growth of a nation's gross domestic product (GDP) [14]. Although evidence for a direct causal relationship remains limited in most cases, there are many acknowledged benefits of SMEs in growing an economy. According to [19], SMEs are labor intensive, providing more opportunities for low-skilled workers, are correlated with lower income distribution inequality, are an important part of the supply chain for large companies and are 'better sites' for innovation and sustainable initiatives due to their inherent flexibility and risk-taking ability.

\subsection{Challenges Faced by SMEs Suppliers}

The majority of SMEs suppliers lack adequate managerial and technical skills as well as the financial capacity to meet the contractual service level agreements of the buying organizations. Most are in business not because they are able to do their jobs, but because they had reasonable resources to start businesses. As a result majority of the SMEs suppliers do not employ the professional commercial practices in running their businesses. For example SMEs suppliers maintain accounting records based on manual accounting systems. This is because of the fact that they regard their businesses as small and they do not afford computerized accounting packages like pastel. These findings are in line with [13] who concluded that the volume of accounting practices in SMEs is dependent on a number of operating environmental factors that include size of the business, business age and industrial grouping. [13] Argued that most owners and managers of SMEs suppliers engage public accountants to prepare required information and that owners and managers search for additional information, but only to a limited extent. [18] Also pointed out that the development of a sound accounting information system (AIS) in SMEs suppliers depends on the owners' level of accounting knowledge. In addition to that the researcher noted that most of the SMEs supplier businesses also lack the appropriate corporate governance structures and systems as well as sound business principles.

\subsection{Strategies for Ensuring that SMEs Suppliers are Reliable in Procurement}

One of the strategies for ensuring reliability of SMEs suppliers was for those in the sector to understand and ask them what it takes it to become a reliable supplier and be prepared for it. They must identify capacity challenges, analyze barriers to entry and seek solutions, enter into partnerships with the aim of capacity-building and invest in their own training and development [1]. This is because the aims and objectives of a SME supplier are equally the same as those of the buying organization. That is to achieve 
success through the attainment of profit, growth in the market share and survival. Since profit is one of the key measurements of success in organizations the development of financial reporting standards for SME suppliers is also critical. This is because achieving positive financial results is one of the key metrics on the performance of a business and a critical consideration by Procurement when choosing to deal with supplier. The SMEs suppliers must be proactive in taking the initiative to understand the industry they are to deal with in order to create a workable relationship. [12] Elaborated that like a tango, a successful contract requires two parties working towards the same goal. As a result there is need to establish or develop some close links between the industry (buying organizations) and the SMEs suppliers. Depending on the value and criticality of the items to be purchased a collaborative relationship will be ideal in defining clearly the expectations of the buying organization as well as the challenges to be faced by the SMEs supplier. Then agree and monitor the measures to be taken in order to achieve the set lead times, to that end, a Service Level Agreement (SLA) has to be put in place to aid the management of the contract relationship between the buying organization and the SMEs supplier.

Governments in developing countries have got also a role to play in ensuring that SME suppliers are reliable in the Supply Chain. This can be done through facilitating the developmental infrastructure, education and avail business economic policies and frameworks which are favorable for business. For example policy inconsistency results in confusion and economic meltdown as it makes strategic planning very difficult for the SMEs suppliers to achieve their targets in line with expectations of their customers (buying organizations).

In addition to the above, for the SME supplier to be considered to be a world class service provider to the buying organization he must be in a position to understand and manage well the issues of finance. This requires the discipline of keeping track of all the sales, cash proceeds and the overall turnover of the business as this helps to determine if the business is making a profit or not. As a matter of fact good record keeping and the management finance is crucial for the success of SMEs suppliers and for them to be reliable suppliers their finances must be on good sound tracking [30]

The International Accounting Standard Board (IASB) introduced an International Financial Reporting Standard (IFRS) designed for use by small and medium-sized entities (SMEs) [17].The introduction of IFRS specifically for SMEs was necessitated by many challenges faced by these entities in adopting full IFRSs in financial reporting, the main aim of which was the excessive disclosure requirements, based on a cost-benefit analysis for SMEs [34]). Small businesses lacking clear financial strategies may achieve some success in the short run, but as soon as competitive conditions stiffen, or an anticipated threat arises, they usually fold. Small to medium businesses must have a basis for differentiating themselves from their competitors, otherwise without the basis; the best the businesses can hope for is mediocrity in the marketplace [6]

In today's global competitive environment, small businesses that do not think and act strategically are extremely vulnerable. All businesses are vulnerable to the forces of a rapidly changing competitive environment, and in future small businesses can expect even greater change and uncertainty, from political changes around the planet, and rapid technological advances to more intense competition and newly emerging global markets. The environment has become more turbulent and challenging for small businesses. To be successful, small companies in a hostile ever- changing environment must go through the process of strategic management [36]

The goal for developing a strategic plan is to create for the small business a competitive advantage. A competitive advantage is a collection of all the factors that sets a small business apart from its competitors and gives it a unique position in the market superior to its competition. From a strategic perspective, the key to business success is to develop a unique competitive advantage, one that creates value for customers and is difficult for competitors to duplicate [3].

Building a competitive advantage alone is not enough; the key success is building a sustainable competitive advantage. A company gains a sustainable competitive advantage through its ability to develop a set of core competences that enables it to serve its selected target customers better than its rivals do [32].

Core competencies are a unique set of capabilities that a business develops in key areas, such as superior quality, customer service, innovation, team building, flexibility and responsiveness that allows it to vault past competitors. Markets, customers and competitors may change, but a business's core competences are more durable, forming the buildings blocks for everything a firm does. Small businesses core competencies have a bearing on their size, their smallness is an advantage that allows them to do things their larger rivals cannot do. The key to success is to build on the core competencies and providing superior service and value for target customers [35].

Entrepreneurs must use a short planning period for their strategic planning. They should be informal and not over structure themselves. The process must be participatory and include employees and outside parties to improve the reliability and creativity of the resulting plan. Entrepreneurs should maintain flexibility and must focus on strategic thinking not just planning, by linking long-range goals to day-to-day operations [9].

According to [32]), entrepreneurs who spell out the vision for their business focus everyone's attention on the future and determine the path the business will take to get there. The vision influences the decisions, no matter how big or how small, that owners, managers and employees make every day in a business. A clear vision excites and ignites people to action. People want to work for an organization that sets its sights high. 


\section{Research Methodology}

This study adopted a qualitative research design because it provided flexibility and afforded the researcher the opportunity to conduct an in-depth research. According to Saunders, [38] there are five research strategies underpinning qualitative research design. These include: experiment, survey, qualitative research, case study, and action research. For this research, a survey on challenges faced in public procurement in Zimbabwe was conducted.

The population for this study was made up of 595 SMEs suppliers in Harare Central Business District (CBD) and 20 officials from SEDCO. This study used stratified random sampling technique when selecting participants from SMEs. SMEs suppliers were grouped into six categories (table 4.1), and the researcher randomly selected $30 \%$ from each group. According to [31], 30\% is an acceptable sample size. The researcher obtained names of SMEs suppliers operating in Harare CBD from the City Health Department, as it is the one which issues shop licenses for suppliers' premises.

SEDCO officers were selected using simple random sampling. The researcher was guided by [31] assertion that $30 \%$ is an acceptable sample size. Accordingly, there were 6 SEDCO officials. Table 4.2 shows population and sample for SEDCO.

Table 4.1. Population and Sample for SMES

\begin{tabular}{lll}
\hline Category of SME & Population & Sample (30\%) \\
\hline Clothing and Footwear & 68 & 21 \\
Foodstuffs & 19 & 6 \\
Electrical and Hardware & 172 & 52 \\
Motor Spares & 114 & 34 \\
Catering & 38 & 11 \\
Stationery and secretarial services & 184 & 55 \\
Total & 595 & 179 \\
\hline
\end{tabular}

Source: City of Harare, Health Department (2013)

Table 4.2. Population and Sample for SEDCO

\begin{tabular}{lll}
\hline Category of Participants & Population & Sample (30\%) \\
\hline SEDCO Harare Office & 20 & 6 \\
Total & 126 & 37 \\
\hline
\end{tabular}

Source: SEDCO (2013)

The researcher made use of interviews as research instruments. Interviews provided a multi-perspective understanding of the issues under investigation and they had the potential to reveal multiple, and sometimes conflicting, attitudes about a given topic [26]. The advantages of using an interview technique were that the respondents expanded on areas of interest and used nonverbal communication such as facial expressions to emphasize their responses. However, interviews were time consuming and expensive to conduct, and they involved protocol in setting up appointments and being granted authority to conduct them.

Data was analyzed using content analysis. [37] Argue that qualitative content analysis involves a process designed to condense raw data into categories or themes based on valid inference and interpretation. The researcher made use of manual data coding system and the formal process of developing the coding scheme began shortly after the first few interviews. After coding the entire data set, the researcher rechecked the consistency of coding. It was not safe to assume that, if data was coded in a consistent and reliable manner, the coding of the whole data was also consistent. Human coders are subject to fatigue and are likely to make more mistakes as the coding proceeds [20] for all these reasons, the researcher had to recheck coding consistency. After rechecking coding consistency, the researcher made inferences and present reconstructions of meanings derived from the data.

\section{Findings}

\subsection{Role of SMEs in Economic Development}

All 6 participants (100\%) from SEDCO pointed out that, SMEs suppliers are important to the economic development of Zimbabwe. Findings from interviews showed that the closure of big industries, especially after Zimbabwe's fast track land reform in 2000, resulted in many people establishing SMEs. In 2012 more than $70 \%$ of the working population was employed by SMEs [24]. Some participants also argued that creation of employment by SMEs will go a long way in reducing crime. SMEs suppliers also help to provide cheap products to customers.

In addition, all six participants from SEDCO (100\%) highlighted that SMEs are vital and this is the reason why SEDCO provide loans to SMEs. The loans can either be working capital loans, repayable in 6 months, or capital financing, which are repaid in one year's time. Interviews with SEDCO officers showed that SEDCO also provide premises to SMEs for example in Glen View where it constructed shelter for furniture manufacturers. SEDCO demands that beneficiaries source $10 \%$ of their total loan requirement. There is also a need for collateral security. New businesses are required to submit their business plans. Established businesses should present an income statement and balance sheet for the previous year. Nevertheless, it was pointed out that the majority of SMEs who requested support did not receive. This was partly due to the high number of SMEs and partly due to the fact that some failed to satisfy loan conditions.

\subsection{Challenges Faced When Dealing with SMEs in Procurement}

A company from the private sector asserted that the majority of the SMEs suppliers are very unreliable, provides poor quality materials and performed below standard. He even testified that on paper their profiles will be very good, showing sound financial stability and good references. From his experience for the past ten years dealing with the SMEs, his organization has scrapped and substituted a number of non performing SMEs from the suppliers list. Their major challenges have been failure to 
meet lead times especially on imported items, poor quality materials. For example an order to provide protective clothing of drill material and before awarding the order. The SME supplier would provide a sample of the correct quality garment material but upon delivery of the rest of the order, he would deliver, wrong poor quality materials and of poor workmanship, thereby resulting in disputes and strained relationships with the buying organization. It is also alleged that in such instances the SMEs suppliers will bribe the purchasing staff to accept the wrong material and this has been a worrying issue in terms of obtaining value for money.

A procurement official from a non-governmental organization highlighted that as much as they would want to deal with the SMEs suppliers and comply with the Government legislation. They would deal with SMEs with extreme caution as many of them were very unreliable. He said they would only allow small value transactions to be dealt with them and for medium high value items they have to be accompanied by a bank guarantee. For high value items they only deal with well-established and reputable organizations because SMEs are considered to be high risk suppliers.

[33] Reported that Amplats of South Africa an Anglo American Platinum producer launched an investigation against Unki Platinum Mine over a multi-million-dollar housing project that has gone sour after allegations of exploitative contracts that were given to Zimbabwean contractors (SMEs). [33] Unki Platinum Mine invited companies to tender for the construction of about 800 units valued at about US\$66 million. Six contractors were awarded the tenders but subsequently the employer's agent, Amplats through its senior projects manager appointed Weldmax Company to be the sole supplier of all the materials for the project valued over US\$26 million. However the deal raised eyebrows, pertaining to the unclear circumstances in which Weldmax was awarded the tender as a sole supplier at the expense of the other six local contractors who had been engaged. Consequently the project lagged behind schedule as basic materials such as bricks, cement and termite poison could not be supplied timeously and the few materials which were delivered could not conform to the right quality specifications captured in the contract.

As a result, the above discussed issues shows some serious challenges which are experienced in dealing with SMEs suppliers and there is need for immediate attention as to how they can be managed in order to bring normalcy and value in the supply chain.

The State Procurement Board of Zimbabwe which is the main administrator of all the public spending by all government institutions and parastatals had this testimony about SMEs suppliers failing to perform after being awarded contracts. [10] Reported that a small to medium enterprise firm was contracted to install and fix elevators at one of the government buildings. Unfortunately five months elapsed without any progress by the contractor besides the fact that he had requested the government to buy the equipment so that he fixes it.

[10] The Minister of Finance reported in the News Day that the ministry gave similar amounts of money to a local (SME) contractor building the Skyline highway and another to the department of public works to carry out the dualization of the Harare- Norton highway. The HarareSkyline work which was undertaken by the department of public works was completed while the Harare Norton road which was being constructed by an independent contractor was way off behind schedule.

[12] reported that a special Ministry of Health and Child Care audit team unearthed a scam at Chivhu General Hospital involving US \$2.5 million dollars, in which officials flouted tender procedures, inflated quotations and also created fictitious ones. It is reported that some tenders were awarded in connivance with the Central Buying Unit officers to companies (SMEs) at inflated prices in order to benefit themselves. For example the auditors found that Markford Distributors which was awarded to supply a BP test machine, charged US\$700 for an item that costs US\$80.00 at Mycote Trading (Pvt) Ltd. Another company, Dial Up Marketing was awarded a tender for $40 \mathrm{~B} / 500$ methylopa $250 \mathrm{mg}$ for US\$5 600 while Leapmed charged US\$2 940.00.

Data Path Systems (Pvt) Ltd was awarded a tender to supply 10 steel rakes for $\$ 600.00$ while the same order would cost $\$ 95.00$ at Fabs Hardware. The same company supplied eight picks for US $\$ 480.00$ when the same quantity of implements costs US\$140.00 at Fabs Hardware.

\subsection{Factors that Hinder SMEs Suppliers from Being Reliable Partners in Supply Chain}

The study revealed that ignorance about the importance of record keeping and accounting information, lack of capacity, and lack of separation between ownership and management of SMEs suppliers hindered some organizations from maintaining accounting records. The study showed that $50 \%$ of the businesses are managed by their owners, $10 \%$ by 'managers' (not related to owner) and $40 \%$ by relatives. Accordingly, it can be seen that corporate governance principles are not applied. In addition, $60 \%$ of participants said that they were not trained for their jobs, they were just fortunate to have capital to start small businesses.

\subsection{Strategies for Ensuring that SMEs Suppliers become Reliable Partners in Supply Chain}

Participants said maintaining accounting records was important for SMEs suppliers to facilitate rational decisionmaking. Accounting is the key to success for any decisionmaking process. Managerial decisions based on facts and figures take the organization to heights of success. An effective pricing policy, satisfied wage structure, collective bargaining decisions, competing with rivals, advertisement and sales promotion policy, all owe it to well set accounting 
structure. Accounting provides the necessary database on which a range of alternatives can be considered to make managerial decision-making process a rational one [5]. Therefore, SMEs suppliers in Harare CBD needed to be concertized about the importance of accounting information.

There was need for SMEs suppliers to formalize their business operations and maintain accounting records. Accounting records would help managers determine whether businesses were making profit. It was vital for SMEs suppliers to send their employees for accounting or simple record keeping courses. This was because most SMEs suppliers did not have accounting records and their employees lacked basic accounting knowledge. There was a need for separation of ownership and control of business affairs. This would ensure more accountability.

\section{Conclusion and Recommendation}

\subsection{Conclusion}

The study revealed the importance and criticality of the relationship between the buying organizations and the SMEs suppliers. The SME supplier organizations have become major players in the economic mainstream of Zimbabwe. They create a reasonable level of employment and contribute to the economic growth of the country. Consequently they have become critical partners in the buying organizations as they have become part of the production processes in the provisioning of the much needed materials. A number of challenges in the performance of SMEs suppliers have been identified and these included failure to meet the delivery schedules, poor quality materials, poor quality work and uncompetitive prices.

\subsection{Recommendations}

\subsubsection{Adoption of professional Procurement Ethics}

There is need for the adoption of professional procurement ethics. As a matter of fact buying organizations must put purchasing in the rightful hands by employing procurement professionals who sign to the Chartered Institute of Purchasing and Supply (CIPS) code of conduct or to their local relevant institute. This is because they have a duty to the profession and to their employers to alert senior management of any corrupt activity. Ethics are embraced at three levels, at national, institutional and at individual meaning that it is the duty of the Procurement professionals to guard against organizations that trade in influence by offering or soliciting for undue advantage at the expense of professionalism to obtain value for money. The adoption of professional Purchasing ethics would minimize if not eliminate some of the issues mentioned in the cases discussed, where some of the SMEs suppliers would try to bribe and solicit for some favors from the procurement staff.

\subsubsection{Supplier Evaluation}

This is done after developing a comprehensive list of potential suppliers and each supplier has to be evaluated in order to determine their capability. Traditionally the choice of a suitable supplier is determined by its compliance to the $5 \mathrm{RS}$ as well as considering the nature of the product in terms of its criticality, complexity and value.

In most developing countries like Zimbabwe, this is where the problem is most experienced as the majority of the SMEs suppliers provide a well-documented and sound company profile on paper but in reality being the opposite. Depending on the value of the items to be purchased, the buying organization needs to determine if the supplier can be managed from the operational point of view or strategic point of view. The competitive/adversarial model or the short-term sourcing refers to the competitive or reactive sourcing which relies on formal paperwork communications rather than personal contact. The relationship is for short-term contracts based on aggressive win-lose approach [7].

However for high-value items, critical or high- technical purchases additional evaluation steps are necessary with the help of other cross-functional team members. Consideration must be done on the financial stability of the SMEs supplier in order to guarantee on the ability for continuation and on time delivery since financially strong firms are usually managerially strong. Plant visits are also important as they are aimed at obtaining first hand information on issues such as technology, manufacturing processes and the management's expertise since a well managed firm rarely experiences instability in terms of labor unrest.

SMEs suppliers are very critical in the supply chain to the extent that they become part of the buying organization's production process, therefore, the buying organization can develop the relationship with the SMEs into a partnership aimed at obtaining a win-win outcome, through the adoption of problem solving approaches. Nevertheless this relationship must be managed carefully as they have a serious impact on their performances in adding value. This can be done by considering, plans to increase trust between the two organizations for example will it be contractual trust, competence trust or good will trust. Plans must always be developed and implemented for training on issues including the designing of variance out of products and processes, quality, procurement, value analysis and engineering, strategic cost analysis, activity-based management. Measurable quantifiable objectives must be established in areas including quality, cost, time as well as technology.

\subsubsection{Communication}

Since most of the SMEs suppliers are the majority suppliers in Zimbabwe and being a government regulation to deal with them. In order to manage them effectively it is important for the buying organizations to strengthen their communication links formally and informally based on ethical grounds. Expedite or chase up suppliers so that lead 
times are met, rate the supplier in terms of performance by scoring him and communicate this information to him so that he is aware. Make him to be responsible for his costly mistakes, for example recover the value of the loss from him or suspend him from the supplier's list. If the SME supplier is very critical, then it will be prudent to develop him and monitor him so that he achieves the right quality and meets the needed lead times. For example Nestle Zimbabwe engaged on a programme to develop and support the small scale farmers to breed the heifers which can produce the quality milk which it can use as raw material to manufacture its milk products such as chocolates and porridge for children.

Let it be very clear that from the private and public sector point of view that any commercial activity with the SMEs must be regarded as business and business is all about making money by adopting the best practices through commitment, honest and transparency in order to obtain value for money for growth, sustainability and development.

\subsubsection{Formalization of Business Operations}

There was need for SMEs suppliers to formalize their business operations and maintain accounting records and to observe the conduct of sound business management based on ethical business leadership skills. Financially strong firms are usually managerially strong and the accounting records would help managers determine whether businesses were making profit or not.

\subsubsection{Training of Employees}

It was vital for SMEs suppliers to send their employees for accounting courses. This was because most SMEs suppliers did not have accounting records and their employees lacked basic record keeping and accounting knowledge.

\subsubsection{Separation of Ownership and Control}

There was a need for separation of ownership and control of business affairs. This would ensure more accountability.

\section{References}

[1] Neema Lugangira Apson, Can Tanzania's Local Suppliers benefit from its New Gas Resources? The International Magazine for Supply Chain Professionals, Volume 18 issue 122013

[2] Younes Benslimane, Michael Plaisent, and Prosper Bernard. Investigating Search Costs and Coordination Costs in Electronic Markets: A Transaction Costs Economics Perspective, Electronic Markets 2005

[3] Dodwell Bill, (Tax Partner at Deloitte) Deloitte the Business Advisory Firm 08th July, 2010

[4] Nigel Caldwell, Jens Roehrich and Andrew Davies. (2009), Procuring Complex Performance in Construction: London Heathrow Terminal 5 and a Private Finance Initiative Hospital, Journal of Purchasing and Supply Management 2009
[5] Mike Chapple, Accounting Data Base, 2010

[6] Uche Chibuike, Accounting History Research: Some Theoretical issues, Nigeria: Lagos: University of Nigeria Virtual Library 2008

[7] Andrew Cox, Win-Win, The Paradox of Value and Interests in Business Relationships, Earls gate Press, London 2004

[8] John Day, The Value And Importance Of The Small Firm To The World Economy, European Journal of Marketing, 34(10), 1033-1037, 2010

[9] Peter Engel, Budgeting and Finance; First Books for Business, McGraw-Hill, San Francisco, 2006

[10] Lloyd Gumbo, Biti Fumes Over Government Tenders, Business Herald, Zimbabwe 2012

[11] Lloyd Gumbo, US\$2.5m Health Scam Exposed, The Herald, Zimbabwe 2013

[12] Geoffrey Hodgson, Making the relationship work, The International Magazine for supply chain professionals Volume 18 issue 12,2013

[13] S. Holmes, and D. Nicholls, Accounting Practices of Small to Medium Enterprises 2008

[14] Hong Kong Institute of Certified Public Accountants, Small and Medium-sized Entity Financial Reporting Framework and Financial Reporting Standard, Hong Kong, 2008

[15] Carol Howorth, and Paul Westhead, The Focus of Working Capital Management in UK Small Firms, Management Accounting Research, 14(2), 94-111,2008

[16] Institute of Chartered Accountancy Zimbabwe 2010, Small and Medium-Sized Entities News, www.icaz.org.zw, Accessed 29 September 2013

[17] International Accounting Standards Board Foundation: Training Material for the IFRS for SMEs, London, 2010

[18] Noor Azizi Ismail, Factors Influencing Accounting Information System Effectiveness Among Manufacturing SMEs: Evidence from Malaysia, The Electronic Journal of Information Systems in Developing Countries, Volume 38, Number 10, 1-19,2009

[19] Noor Azizi Ismail, and Rosliza Zin, Usage of Accounting Information among Malaysian Bumiputra Small and Medium Non-Manufacturing Firms, Journal of Enterprise Resource Planning Studies, 1-7,2009

[20] Chakravanti Rajagopalachari Kothari, Research Methods and Techniques, New Age Publishers, New Delhi, 2004

[21] Michael Lewis, and Jens Roehrich, Contracts, Relationships and Integration: Towards a Model of the Procurement of Complex Performance, International Journal of Procurement Management, 2009

[22] Edit. Lukacs, The Economic Role of SMEs in World Economy, Especially in Europe, European Integration Studies, 4(1), 3-12, 2009

[23] John Mangan, Chandra Lalwani and Tim. Butcher, Global Logistics and Supply Chain Management, John Wiley and Sons, New Jersey, 2008 
[24] Takunda Maodza, Small and Medium Enterprises Survey Report, Zimstats 2013

[25] Enacy Mapakame, Structural Changes in the Economy, The Sunday Mail Business, Zimpapers, 2014

[26] Geoffery Marczyk, David DeMatteo, and David Festinger, Essentials of Research Design and Methodology, John Wiley and Sons, New Jersey, 2005

[27] Robert Maurer, One Small Step Can Change Your Life; The Kaizen Way, Workman, 2004

[28] Scott Moore, Organizational Development and Management; Small and Micro Enterprise 2008

[29] Bahar Movahedi, Kayvan Miri Lavassani Vinod Kumar, Transition to B2B e-Marketplace Enabled Supply Chain: Readiness Assessment and Success Factors, The International Journal of Technology, Knowledge and Society, Volume 5, Issue 3, 2009

[30] Clive Mphambela, Record Keeping Crucial for Successful SMEs, Newsday, Business, Aplha Media, Harare, 2013

[31] Nontando Msipa, Entrepreneurial training needs analysis, The Zimbabwean Ministry of Small To Medium Enterprises Policy 2002

[32] Vincent Muro, Handbook of Financial Analysis for Corporate Managers, AMACOM, New York,2008

\section{Biography}

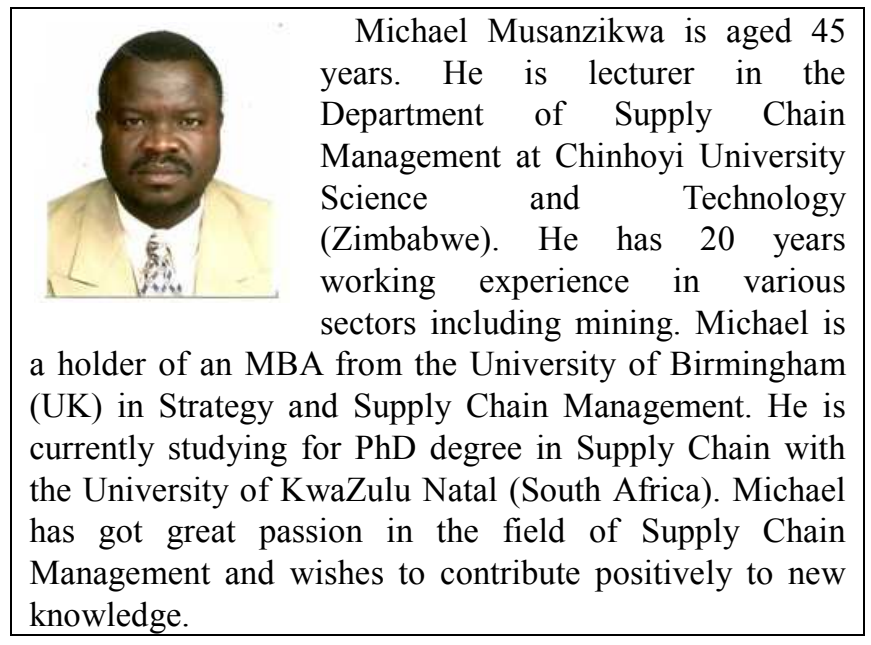

[33] Darlington. Musarurwa, Unki Platinum Mine under investigation, The Sunday Mail Zimbabwe 2013

[34] Mohd. Nazri, A standard for SME Financial Reporting, SME Toolkit Malaysia, August 2010

[35] Derek Newberry, The role of Small and Medium Sized Enterprises in the Future of Emerging Economies, World Research Institute, New York, 2006

[36] Tracy Penwell, Strategic Management in Small Firms 2004

[37] Jane Ritchie and, Jane. Lewis, Qualitative Research in Practice, A Guide for Social Sciences Students and Researches, Sage Publishing, New Delhi, 2003

[38] Mark Saunders, Philip Lewis, and, Adrian Thorn hill, Research Methods for Business Students, Sixth Edition, Prentice-Hall, London, 2012

[39] Felecia Shaw, The Power to Procure: A Look inside the City of Austin Procurement Program, Applied Research Projects, Texas State University,2010

[40] Small Enterprise Development Corporation (2010), Small and Medium Enterprises, www.sedco.co.zw Accessed 30 September 2013

[41] Andreas Wieland and Carl Marcus. Wallenburg Supply Chain Management, Zeiten, Berlin, 2011 